\title{
Abscopal effect of radiation on lung metastases of hepatocellular carcinoma: a case report
}

\author{
Kae Okuma ${ }^{1}$, Hideomi Yamashita ${ }^{\text {*}}$, Yuzuru Niibe ${ }^{2}$, Kazushige Hayakawa $^{2}$, Keiichi Nakagawa ${ }^{1}$
}

\begin{abstract}
Introduction: The abscopal effect is the effect of radiation therapy at a site distant to the area of irradiation. This is not a common event and has not been clearly defined, resulting in few reported cases in the literature. We discuss this phenomenon in a patient with hepatocellular carcinoma.

Case presentation: A 63-year-old Japanese man underwent extended right hepatic lobectomy for hepatocellular carcinoma. During his follow-up examination, a single lung metastasis and a single mediastinal lymph node metastasis were found. Trans-catheter arterial embolization was initially attempted to treat the mediastinal tumor, however this approach failed to take effect and carried risks of spinal artery embolism. External-beam irradiation, with a dose of 2.25 Gy per fraction, was performed using an antero-posterior parallel-opposed technique (total dose, 60.75 Gy). A computed tomography scan performed one month after starting radiotherapy showed a remarkable reduction of the mediastinal lymph node metastasis. In addition to this, we observed spontaneous shrinking of the lung metastasis, which was located in the right lower lobe and out of the radiation field. No chemotherapy was given during the period. There has been no recurrence of either the lung metastasis or the mediastinal lymph node metastasis during a follow-up 10 years after the radiotherapy.
\end{abstract}

Conclusion: We observed a rare abscopal effect in a site distant from the area of irradiation. Irradiation of the mediastinum resulted in tumor mass regression in the untreated lung tumor.

\section{Introduction}

An abscopal effect has been defined as a reaction outside an irradiated area but within the same organism [1], that can result in a tumor in a non-irradiated area being spontaneously reduced. Since the first report of an abscopal effect by Mole in 1953 [2], several other cases have been reported in malignant lymphoma [3-5], hepatocellular carcinoma (HCC) [6] and malignant melanoma [7]. In 2007, Takaya et al. described an abscopal effect in a case of toruliform para-aortic lymph node metastasis in a patient with advanced uterine cervical carcinoma. This patient was treated with external whole-pelvis and intra-cavitary irradiation to the primary pelvic lesion, successfully resulting in disappearance of the lesion. Moreover, para-aortic lymph node metastases outside the irradiated field also spontaneously disappeared [8].

\footnotetext{
* Correspondence: yamashitah-rad@h.u-tokyo.ac.jp

'Department of Radiation Oncology, University of Tokyo Hospital, 7-3-,1

Hongo, Bunkyo-ku, Tokyo 113-8655, Japan

Full list of author information is available at the end of the article
}

The mechanism of the abscopal effect has not been clearly defined. We report here the case of a patient who showed an abscopal effect on lung metastases of HCC.

\section{Case presentation}

A Japanese man, who had been followed since 53 years of age by the respiratory department of our Medical Center due to bronchial asthma, was hospitalized for progression of asthma at 63 years old. A suspected diagnosis of HCC in his right liver lobe was confirmed by abdominal computed tomography (CT). An extended right lobectomy was performed after three months in our hospital. Pathologic examination revealed an HCC, composed of a necrotic tumor that measured $10.5 \times 9 \times$ $11 \mathrm{~cm}$. In addition, there were three daughter nodules with diameters of less than $1 \mathrm{~cm}$ each. The residual nodular tumor without necrosis was Edmondson grade II to III with nuclear atypia, and was moderately differentiated. Invasion of lymphatic and vascular channels was not obvious. Exposure to the surface of the liver 
capsule was not found. A single lung metastasis and a single mediastinal lymph node metastasis were found in a chest CT scan performed 18 months after the liver lobectomy (Figures 1 and 2). Final diagnosis was made based on the elevated levels of two tumor markers for HCC: $\alpha$-fetoprotein (AFP) (4869 $\mathrm{ng} / \mathrm{mL})$ and protein induced by vitamin $\mathrm{K}$ absence or antagonists II (PIVKAII) $(>20,000 \mathrm{mAU} / \mathrm{mL})$. Trans-catheter arterial embolization for the mediastinal tumor was attempted, however the risk of spinal artery embolism resulted in the decision to only examine the tumor at that time.

Our patient was admitted to our Department of Radiation Oncology for irradiation. His Karnofsky performance status score was $90 \%$ to $100 \%$. He complained of a moderate cough and moderate bloody sputum but denied any dyspnea or chest pain. To relieve these clinical symptoms, external-beam irradiation, with a dose of 2.25 Gy per fraction, was performed using an anteroposterior parallel-opposed technique (total dose, 60.75 Gy) (Figures 3 and 4). The energy was 10 megavolts. The radiation field was set for gross tumor volume plus a margin of $1 \mathrm{~cm}$. The field size was $8 \times 10 \mathrm{~cm}$. Radiation therapy was given four times a week. After $40 \mathrm{~Gy}$, the radiation field was changed to left-right parallelopposed beams to spare the spinal cord (Figure 5). The lung metastasis that had induced no clinical symptoms was not treated with radiation therapy, and was located outside the radiation field of the left-right opposing beams (Figure 6). A CT scan was performed after the radiation therapy, which showed a remarkable reduction in the mediastinal lymph node. Additionally, shrinking of the tumor in his right lower lobe, outside of the radiation field, was observed (Figures 7 and 8). No chemotherapy had been given during this period.

During follow-up as an out-patient, our patient was observed to have dyspnea (Hugh-Jones 1-2), slight cough and slight sputum. AFP levels had decreased to $23 \mathrm{ng} / \mathrm{mL}$, and PIVKA-II to $13 \mathrm{mAU} / \mathrm{mL}$.

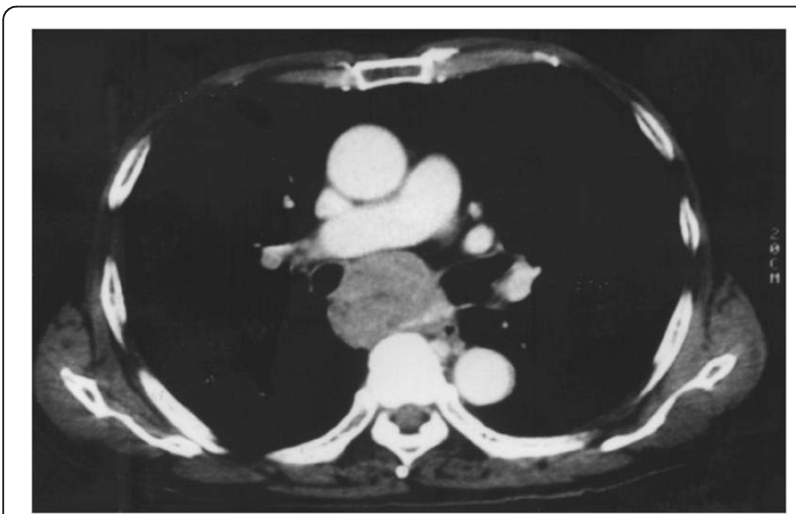

Figure 1 Chest CT image before radiation therapy. A bulky mediastinal lymph node metastasis was detected.

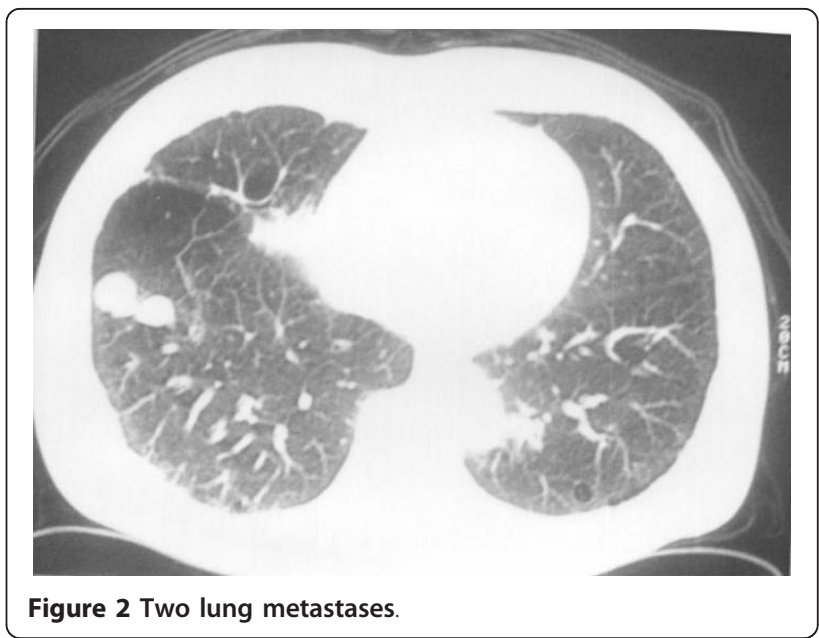

A CT scan performed four years after the radiation therapy showed a lymph node swelling with a diameter of $3.5 \mathrm{~cm}$ in the area of origin of the left gastric artery. At this time, AFP and PIVKA-II were elevated to 1990 $\mathrm{ng} / \mathrm{mL}$ and $1990 \mathrm{mAU} / \mathrm{mL}$ respectively, but with no pathologic evidence of recurrence. Stereotactic body radiotherapy for the lesion was performed, with $30 \mathrm{~Gy}$ in three fractions. The recurrent tumor disappeared. Six and a half months after the stereotactic body radiotherapy, no obvious recurrent disease was found.

\section{Discussion}

Many case reports describing spontaneous regression of HCC can be found in the literature. Since 1982, about 60 cases have been reported as abscopal effects or spontaneous regressions. These cases were reviewed by Oquiñena et al. in 2009 [9]. Although many similar reports have been published $[3,4,6-8,10]$, the abscopal

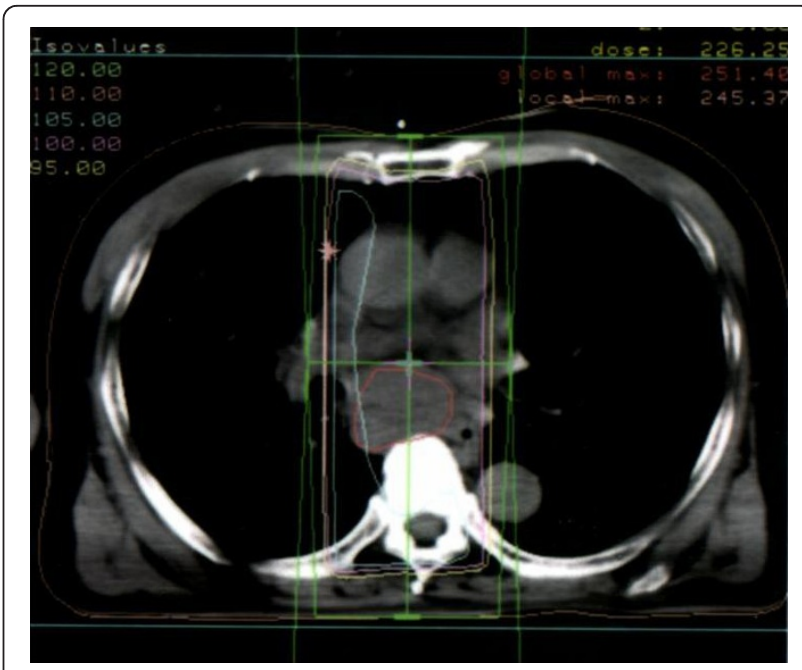

Figure 3 Chest CT image showing radiation dose distribution: axial view. 


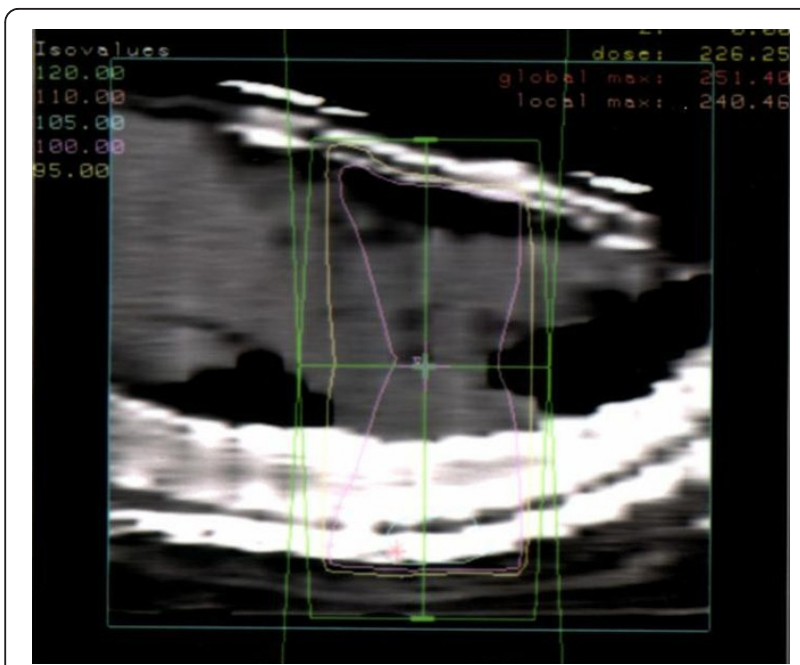

Figure 4 Chest CT image showing the radiation dose distribution: sagittal view.

effect is still a rare phenomenon, and the mechanism has not been clearly defined. Lin et al. proposed two mechanisms involving ischemia and an immune response [11]. First, mitotic inhibitors (cytokines) induced by local radiation are released into the circulation and mediate a systemic anti-tumor effect. This hypothesis is supported by reports that circulating tumor necrosis factor levels are elevated after radiotherapy, and have coincided with the regression of an HCC situated away from the radiation field $[2,12]$. Second, irradiation of a tumor in one site induces the release of circulating tumor antigen or inflammatory factors, which may then mediate an augmented immune response against non-irradiated, malignant lesions expressing similar tumor antigens. It has previously been shown that local radiotherapy increases the activity of natural killer cells $[13,14]$. Dewan et al. presented the hypothesis that the type of dose fractionation regimen determines the ability of radiotherapy to synergize with

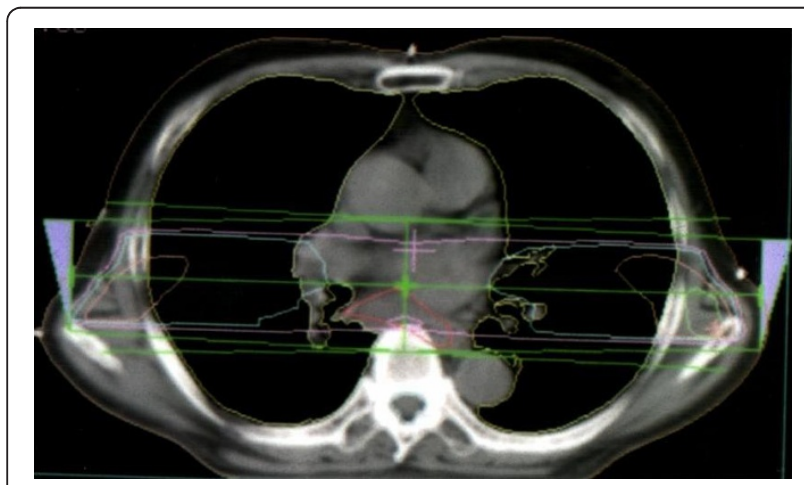

Figure 5 Chest $\mathrm{CT}$ image showing radiation dose distribution after $40 \mathrm{~Gy}$.

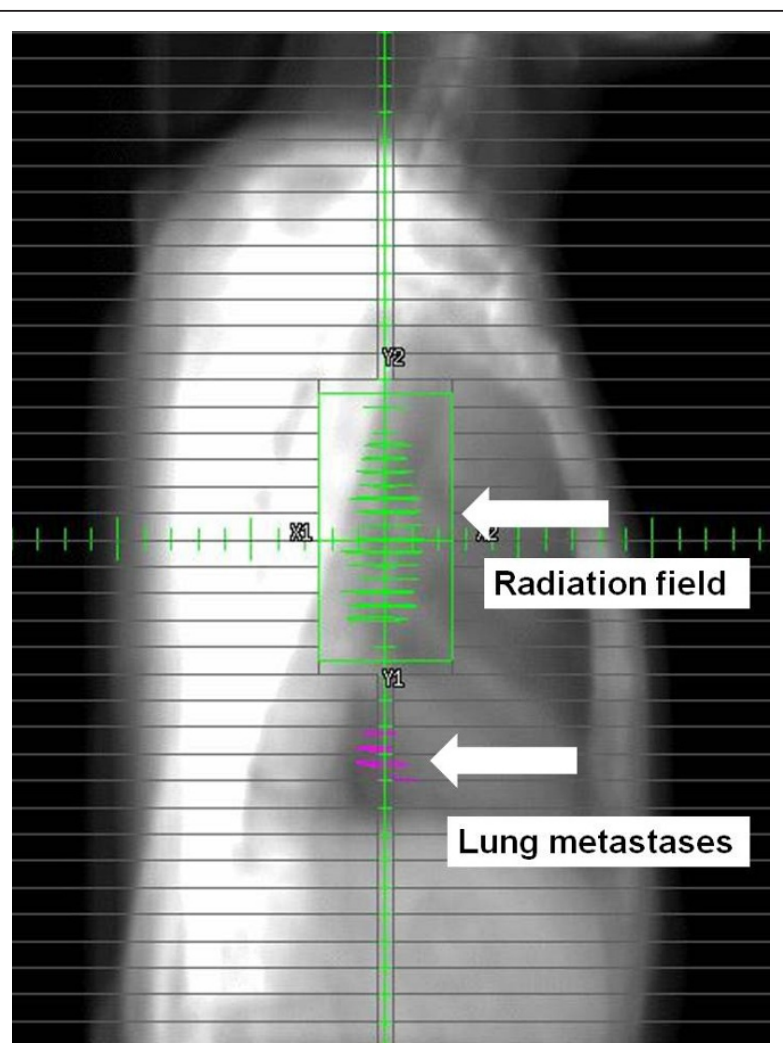

Figure 6 Beam's eye view of the lateral beam of the radiation therapy. This shows the metastatic lung tumor is outside the target area.

anti-CTLA-4 antibody [15]. Although these hypotheses have some merit, at present they remain to be confirmed.

\section{Conclusion}

We observed a rare abscopal effect in a site distant from the area of irradiation. Irradiation of a tumor in the

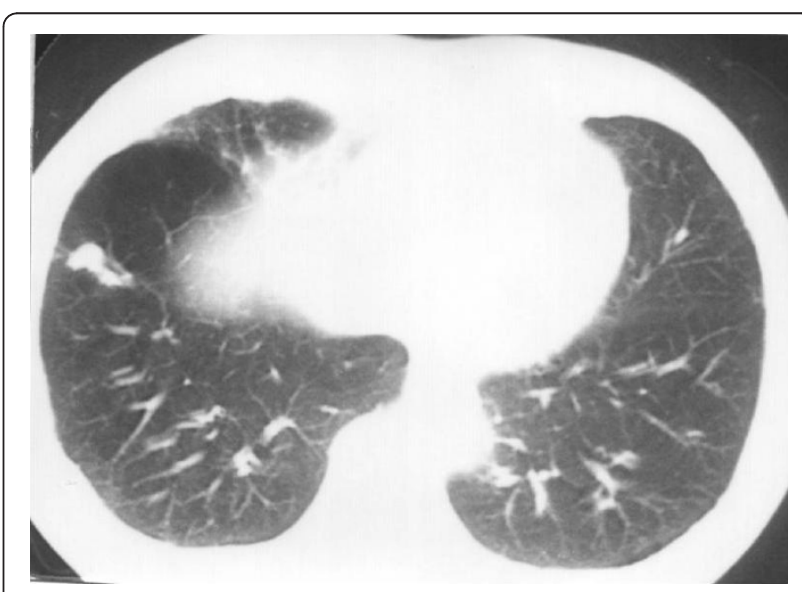

Figure 7 Chest CT scan after radiation therapy. Both lung metastases had shrunk under radiation therapy. 


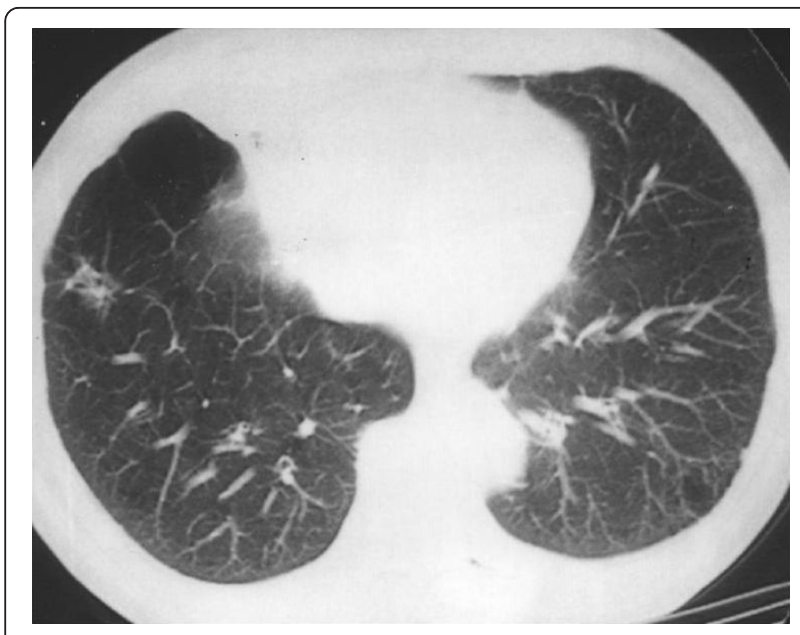

Figure 8 CT scan showing the absence of both lung metastases, which regressed after radiation therapy.

mediastinal resulted in tumor mass regression in an untreated lung metastasis of HCC.

\section{Consent}

Written informed consent was obtained from the patient for publication of this case report and any accompanying images. A copy of the written consent is available for review by the Editor-in-Chief of this journal.

\section{Author details}

'Department of Radiation Oncology, University of Tokyo Hospital, 7-3-,1 Hongo, Bunkyo-ku, Tokyo 113-8655, Japan. ${ }^{2}$ Department of Radiation Oncology, Kitasato School of Medicine, 1-15-1, Kitasato, Minami-ku, Sagamihara, Kanagawa 252-0375, Japan.

\section{Authors' contributions}

$\mathrm{KO}$ undertook the gathering of information for this case and was a major contributor in writing the manuscript. HY conceived the manuscript and was a major contributor to the manuscript. All authors read and approved the final manuscript.

\section{Competing interests}

The authors declare that they have no competing interests.

Received: 19 May 2010 Accepted: 19 March 2011

Published: 19 March 2011

\section{References}

1. Niibe $Y$, Hayakawa K: Oligometastases and oligo-recurrence: the new era of cancer therapy. Jpn J Clin Oncol 2010, 40(2):107-111.

2. Mole RH: Whole body irradiation: radiobiology or medicine? $\mathrm{Br} J$ Radiol 1953, 26(305):234-241

3. Nobler MP: The abscopal effect in malignant lymphoma and its relationship to lymphocyte circulation. Radiology 1969, 93(2):410-412.

4. Antoniades J, Brady LW, Lightfoot DA: Lymphangiographic demonstration of the abscopal effect in patients with malignant lymphomas. Int J Radiat Oncol Biol Phys 1977, 2(1-2):141-147.

5. Rees GJ: Abscopal regression in lymphoma: a mechanism in common with total body irradiation? Clin Radiol 1981, 32(4):475-480.

6. Ohba K, Omagari K, Nakamura T, Ikuno N, Saeki S, Matsuo I, Kinoshita H, Masuda J, Hazama H, Sakamoto I, Kohno S: Abscopal regression of hepatocellular carcinoma after radiotherapy for bone metastasis. Gut 1998, 43(4):575-577.

7. Kingsley DP: An interesting case of possible abscopal effect in malignant melanoma. Br J Radiol 1975, 48(574):863-866.

8. Takaya M, Niibe Y, Tsunoda S, Jobo T, Imai M, Kotani S, Unno N, Hayakawa K: Abscopal effect of radiation on toruliform para-aortic lymph node metastases of advanced uterine cervical carcinoma-case report. Anticancer Res 2007, 27(1B):499-504.

9. Oquiñena S, Iñarrairaegui M, Vila JJ, Alegre F, Zozaya JM, Sangro B: Spontaneous regression of hepatocellular carcinoma: three case reports and a categorized review of the literature. Dig Dis Sci 2009, 54(5):1147-1153

10. Lakshmanagowda PB, Viswanath L, Thimmaiah N, Dasappa L, Supe SS, Kallur P: Abscopal effect in a patient with chronic lymphocytic leukemia during radiation therapy: a case report. Cases J 2009, 2:204.

11. Lin TJ, Liao LY, Lin CL, Shih LS, Chang TA, Tu HY, Chen RC, Wang CS: Spontaneous regression of hepatocellular carcinoma: a case report and literature review. Hepatogastroenterology 2004, 51(56):579-582.

12. Hall E: Radiobiology for the Radiologist. Philadelphia: Lippincott, Williams and Wilkins, 5 2000, 588.

13. Uchida A, Mizutani $Y$, Nagamuta $M$, Ikenaga $M$ : Effects of $X$-ray irradiation on natural killer (NK) cell system. I. Elevation of sensitivity of tumor cells and lytic function of NK cells. Immunopharmacol Immunotoxicol 1989, 11(2-3):507-519.

14. Demaria S, Ng B, Devitt ML, Babb JS, Kawashima N, Liebes L, Formenti SC: lonizing radiation inhibition of distant untreated tumors (abscopal effect) is immune mediated. Int I Radiat Oncol Biol Phys 2004, 58(3):862-870.

15. Dewan MZ, Galloway AE, Kawashima N, Dewyngaert JK, Babb JS, Formenti SC, Demaria S: Fractionated but not single-dose radiotherapy induces an immune-mediated abscopal effect when combined with anti-CTLA-4 antibody. Clin Cancer Res 2009, 15(17):5379-5388.

doi:10.1186/1752-1947-5-111

Cite this article as: Okuma et al: Abscopal effect of radiation on lung metastases of hepatocellular carcinoma: a case report. Journal of Medical Case Reports 2011 5:111.

\section{Submit your next manuscript to BioMed Central and take full advantage of:}

- Convenient online submission

- Thorough peer review

- No space constraints or color figure charges

- Immediate publication on acceptance

- Inclusion in PubMed, CAS, Scopus and Google Scholar

- Research which is freely available for redistribution
Biomed Central 